\title{
1 \\ Work, employment and human resource management: Case study applications
}

Tony Dundon and Adrian Wilkinson

Many textbooks on HRM and Industrial Relations combine discursive, prescriptive, theoretical and sometimes a critical synthesis of the practical applications of abstract concepts and ideas. As a field of study, HRM covers a wide remit associated with work, employment and organisational studies. Academic disciplines overlap between sociology, economics, law, history or industrial and organisational psychology (among others) (Boxall and Purcell, 2016; Wilkinson et al., 2017, 2019; Bratton and Gold, 2019). Most approaches have the admirable aim of synthesising information and concepts to impart a degree of knowledge. Some even seek to contrast alternative or differing interpretations of such knowledge with demonstration through models, frameworks, contemporary innovations that relate to evolving contexts and scenarios for application.

However, these are not neutral or apolitical applications of knowledge (Dundon et al., 2017). Understanding the antithesis of alternative knowledge paradigms is an important part of scholarship and learning, and unpacking various discourses can underscore particular managerial or other corporate vested-interests (Bridgman et al., 2016). In HRM this relates to what Legge (1995) famously described as contrasting rhetoric and realities in the world of work. Contemporary debates might include, for example, the ‘\#996 approach' to work and employment. For some business leaders - key among them being Jack Ma, the co-founder of giant online shopping platform Alibaba - the \#996 approach is to encourage 12-hour working days (9am-9pm), 6 days a week. ${ }^{1}$ For corporate leaders such an approach can open up new opportunities for increasing the earning capacity for millions of poor people, many in less developed parts of the world. However, it is probable that increasing low paid jobs will generate even more wealth for business leaders than it does in uplifting the share in national income or wealth distribution for workers. The narrative of offering new earnings opportunities, or claims for more efficient flexibility, typically means exploiting others lower down the hierarchy and the workers required to labour 9am-to-9pm, 6 days a week. Indeed, extending critical synthesis and research knowledge may illustrate that not only does \#996 benefit a few at the top, at the expense of workers, it is also unsustainable and counter-productive to long-term productivity (Batt, 2018). For instance, long hours runs against the research evidence about employee well-being, mental health, organisational productivity and individual stress (Guest, 2017).

The purpose of this book is to provide a bank of evidence-based case studies that offer critically informed applications for students and educators. Taken together they represent a set of developed materials in which knowledge generation can be extended through application and critical analysis, reflection and synthesis. In part, the demand for the book arose from conversations about the 
difficulties of integrating critical analysis and engagement for students because of the way much university learning has been developing, particularly in business school environments. Many texts and modules present very brief scenarios of ideas and theories, with condensed hypothetical situations for students to consider the concepts and theories they are studying. Large student numbers mean that seminars and tutorials are less frequent as spaces for debate and discussion, and even when they do exist, the increasing numbers in such groups means that student reflection is more difficult to sustain.

The cases in this volume have been derived from scholarly research into one or more specific work, employment, HR and/or organisational analysis topics. They lend themselves as supplementary learning materials with the specific aim of encouraging students to apply knowledge and debate alternatives to those of the more prescriptive managerial and vested-interest language. For the majority, the cases in this volume are anchored from ongoing research projects and analysis of the respective chapter authors. In other words, these case studies are first and foremost real world situations, written by leading scholars from the fields of industrial relations, HRM, work and employment studies, work sociology, organisational psychology, labour economics, the law, and organisational analysis. The audience is students and educators seeking materials for critical analysis and reflection at higher or advanced levels of study and those interested in the world of work, employment and/or organisational analysis. It is relevant for those on a range of cognate masters' programmes in human resource management, work and organisation studies, industrial relations, and related MBA modules found at many educational institutions. They are NOT puff pieces for organisations but are research based and critical in their approach.

\section{STRUCTURE OF BOOK AND CASES}

The cases vary and are presented in the book by related thematic content, concerned with the world of work and the management and application of organisational practices and ideas.

In Section I there are four case studies covering in some detail what may be defined as 'people resourcing. Several debatable issues surround how corporations recruit and select employees for jobs. Scholarios and Hurrell and Hurrell, Mazzoni and Scholarios cover these issues in Chapters 2 and 3, respectively, drawing on research from a case in legal services (recruitment) and the finance sector (selection). Following this, Roe and Athelstan-Price, in Chapter 4, report a case about well-being policy along with how representation can function to support workers with autism. These 'people resourcing' dynamics include not only how companies recruit, select and manage well-being, but also the challenges and pressures surrounding flexibility and issues about people exiting an organisation during times of austerity. In Chapter 5 Johnstone and Procter report on the case of flexible working in recession and recovery.

Section II then shifts attention to cases reporting on 'HR strategy, rewards and performance'. Six cases report debates across multiple organisational types; for example, implementing HR strategy in small firms (e.g. the coffee shop club) in Chapter 6 by Kellner, and pay and remuneration in a public sector authority, from Johnson in Chapter 7. These debates are captured and extended further with a case about High Performance Work Systems (HPWS) in Chapter 8, from Knies et al. 
Performance management is presented in a case by Gould and O'Donohue in Chapter 9. Next, in Chapter 10, gender pay and pay gaps are addressed by Woodhams et al.; and in Chapter 11, issues about pay equality and public policy debates are discussed by Prowse et al. with a case about living wage campaigns.

Section III then directs attention to some of the key complexities in 'workplace relations and voice', with six case studies that offer plenty to discuss and debate. For example, in Chapter 12 Cullinane et al. outline the use of double-breasting voice and transnational employment regulations. Related is the case in Chapter 13 that contrasts Ryanair in Europe with Southwest Airlines in the US, capturing issues of union recognition from long established research in this sector by Harvey and Turnbull. In Chapter 14 Michael Walker reviews the phenomenon that is the so-called Uberization of employment issues and labour market legal reform. The issues that link employee engagement with alleged voice outcomes is reported in Chapter 15 by Robinson, followed in Chapter 16 by a case of workplace resistance in a bespoke small batch gin manufacturer, from Murphy et al. Contemporary developments and important debates about insecurity and employment precariousness can be found in the case in Chapter 17, from O'Sullivan, reporting on zero hours work and attendant employment contracts in the well-known retail outlet Sports Direct.

Section IV groups together six cases capturing 'Human resource development, diversity, skills and training. The core issue of skill and how 'learning by doing and telling' is delivered in the fire service is reported in Chapter 18 from Brooks, Grugulis and Cook. Next, the challenges associated with 'developing talent' are covered in Chapter 19 by Wiblen, followed by a case that opens up debate on the meaning of 'competence', from Winterton and Turnbow in Chapter 20. How the Victoria State Police in Australia manage gender diversity is shown in Chapter 21 by Georgina Caillard and Julie Wolfram Cox. A number of these underlying themes are picked up more specifically by Deakin and Hoel in Chapter 22, when debating bullying in the workplace. Next, Kate Hardy, in Chapter 23, provides a platform to evaluate issues of labour (de)commodification and inclusion for groups of workers that are typically missing in mainstream texts, namely the concerns of sex workers.

Section V includes another six cases that address themes of 'culture and job quality'. In Chapter 24 Rafferty reviews a well-known class-law suit at Microsoft Corp, contrasting the masculinity of HR control and its impact on diversity and the issues of stereotyping. Culture features as a key issue in Donnelly's case in Chapter 25 about changing organisational hierarchies and boundaries, with particular relevance to knowledge-intensive type environments. Cultural facets pervade workplace well-being in Chapter 26 from Ressia et al. Warhurst and Wright provide a case in which public policy in Scotland is used to promote an active agenda to enrich job quality cultures for lower paid occupations. In Chapter 28 Been and Payton chart new terrain with a case about freelancers and work quality issues unique to the gaming industry, providing contrasting insights across computer gaming programmers. Then, in Chapter 29, Timming presents two case comparisons to show how body art (tattoos) can enhance corporate brand and culture.

Next there are four chapters in Section VI, that between them tackle critically the meanings and applications of 'leadership and change'. In the first of these, in Chapter 30, McCann explains that while being a leader is difficult and a thankless challenge, it can nonetheless have a sinister and highly controlling motive. Important from McCann's case is the need to unpack what are often 'meaningless' pockets of espoused wisdom from management leadership gurus. Next, in Chapter 
31 by Harney and Dundon, the case of Amazon shows the 'ideology of hard leadership' and the HR impacts from neo-liberalism on employees' working lives. In Chapter 32 Langerud and Jordan review ideas of transformational leadership by examining the specific case of the Ford Motor Company. Next, in Chapter 33, Said draws distinctions between micro and macro leadership facets when outlining the performance change from a New Public Management (NPM) leadership agenda in a developing country context.

Section VII directs attention to 'international HRM', with seven chapters. Lavelle, Gunnigle and Monaghan in Chapter 34 report a case about the HR function at a multinational subsidiary. It draws on challenges of change and continuity and how processes are mediated across complex organisational layers. In Chapter 35 Kynighou draws on expatriate HR issues and competing demands between local and global contextual pressures. McDonnell et al., in Chapter 36, address several issues concerned with how multinational corporations manage international staff mobility. Extending the global HR dimensions in Chapter 37, Lee Cooke provides some insight about the transformation of one of China's fastest growing and redeveloped MNCs, Haier, focusing on the implementation of people management strategy. Next, specific country of origin approaches provide further opportunities to contrast related HR and employment issues in the United Arab Emirates (Chapter 38, by Zeffane and Kemp), South Africa (Chapter 39, by Bischoff and Wood) and Australian expats (Chapter 40, by Despotovic).

The final section includes three chapters that extend debates and issues related to globalisation, with a particular concern with 'global labour rights' and labour standards across multinational corporations and supply chains. In Chapter 41 Chan provides a case of labour degradation and how workers have been treated in Foxconn, one of the largest suppliers of components that feature in smartphones and other electronic devices. Next, in Chapter 42, Mustchin et al. provide evidence from their research into the negotiation of framework agreements at Volkswagen, debating the important role of trade union actors. Finally, Chapter 43 concludes the section with an important case about worker safety and the power of collective organisation. In this chapter, Jenkins provides case evidence to showcase to students how power asymmetries remain permissive alongside (or because of) voluntary enforcement codes, offering critical analysis of corporate responsibility narratives. Taken together, the cases in Section VIII illustrate that issues of workplace safety, hazardous employment and labour agency are not isolated incidents but pervade countries, continents and multinational organisational types.

\section{CONCLUSION: THEMES AND STRUCTURE}

All the cases in this volume are contemporary, relevant and cover different sectors, countries, occupations and experiences. As a bank of evidence-based cases, the collection in its own right is significant and unique. In an era when academics are pressurised to publish in top journals in addition to (in some countries) having to demonstrate impact reports from their research, it is important not to lose sight of the important impact we, as educators, have on students. These cases may help to stimulate and inform students of research-focused approaches to scholarship and the application of research in teaching. 
The cases are also important given the timing of many of the research enquiries from which they are drawn, including the synthesis of work and employment debates that extend beyond the global financial recession. While the sections provide some order, there are overlapping themes and issues between these, and educators may find a case in one particular section can be used for issues they want to address in another. Given the field of study, many of the cases illustrate the capacity-building power and role of agency as a collective dynamic for change and improvement for people. Second, structures of accumulation matter. How corporate enterprises respond to and shape global forces amplifies the political tensions that shape work, employment and organisational analysis. These issues extend to a policy-driven agenda from research engagement. Finally, the collection of case studies shows how a multi-disciplinary approach can inform knowledge to those issues and concerns that extend beyond a single organisation or groups of actors.

The aim has been to include case studies that are specific, critical and focused and do NOT invite students to walk in the shoes of managers, by trying to fix some presumed corporate problem for a managerial class or other corporate vested-interest group. Instead, they are cases that apply social science analysis of issues of a field of study to review, to discuss concepts, and to debate impacts on and for a wider stakeholder groups and agency interests.

\section{END NOTES}

1 Jack Ma defends the 'blessing' of a 12-hour working day, BBC News, 5th April 2019 (https://www.bbc.co.uk/news/business-47934513).

\section{REFERENCES}

Batt, R. (2018), 'The financial model of the firm, the "future of work”, and employment relations', in A. Wilkinson, T. Dundon, J. Donaghey and A. Colvin (eds), The Routledge Companion to Employment Relations, London: Routledge.

Boxall, P. and Purcell, J. (2016), Strategy and Human Resource Management, 3rd edn, New York: Palgrave Macmillan.

Bratton, J. and Gold, J. (2019), Human Resource Management: Theory and Practice, 6th edn, Basingstoke: Palgrave.

Bridgman, T., Cummings, S. and Mclaughlin, C. (2016), 'Re-stating the case: How revisiting the development of the case method can help us think differently about the future of the business school', Academy of Management Learning, 15(4), 724-41.

Dundon, T., Cullinane, N. and Wilkinson, A. (2017), A Very Short, Fairly Interesting and Reasonably Cheap Book About Employment Relations, London: Sage.

Guest, D. (2017), 'Human resource management and employee well-being: Towards a new analytic framework', Human Resource Management Journal, 27(1), 22-38.

Legge, K. (1995), Human Resource Management, Basingstoke: Macmillan Business.

Wilkinson, A., Redman, T. and Dundon, T. (2017), Contemporary Human Resource Management: Text and Cases, 5th edn, London: Pearson.

Wilkinson, A., Bacon, N., Snell, S. and Lepak, D. (2019), The Sage Handbook of Human Resource Management, 2nd edn, New York: Sage. 